\title{
Trabzon ve Rize kıyılarındaki T-mahmuzların plaj olarak kullanılabilirliği üzerine alan çalışması
}

\author{
A case study on the usability of T-head groins as beach at Trabzon and Rize coasts
}

\author{
Veli SÜME ${ }^{1, a}$, Turan YÜKSEK ${ }^{2, b}$, Ayberk KAYA* ${ }^{1, c}$ \\ ${ }^{I}$ Recep Tayyip Erdoğan Üniversitesi, Mühendislik Fakültesi, Inşaat Mühendisliği Bölümü, 53100, Rize \\ ${ }^{2}$ Recep Tayyip Erdoğan Üniversitesi, Güzel Sanatlar Tasarım ve Mimarlık Fakültesi, Peyzaj Mimarlığı Bölümü, 53100, Rize
}

• Geliş tarihi / Received: 23.02.2019 • Düzeltilerek geliş tarihi / Received in revised form: 05.05.2019 • Kabul tarihi / Accepted: 23.05 .2019

\begin{abstract}
$\ddot{O} \mathbf{z}$
Ülkemizin Doğu Karadeniz Bölümü eğimli ve engebeli arazi yapısına sahip olup; arazi pek çok yerde akış hızı yüksek irili ufaklı çok sayıda dere ile parçalanmıştır. Şiddetli sağanak yağışların etkili olduğu yörede akarsu ve kıyı erozyonu çok önemli bir çevre sorununa neden olmaktadır. Diğer önemli bir sorun ise, sahil boyunca dereler ve kıyı akıntıları ile taşınan katı materyallerin, derelerle denizin birleştiği noktalarda dolma problemlerinin yaşanmasına neden olmasıdır. Aynı zamanda limanların, çekek yerlerinin ve balıkçı barınaklarının dolarak sığlaşmasına ve işlevlerini tam olarak yerine getirmesine engel olmaktadır. Akarsu ve kıyı erozyonu sonucunda önemli yaşam alanları, kıyı yerleşimleri tahrip olmakta ve bunun sonucunda çok ciddi ekonomik kayıplar meydana gelmektedir. Akarsu ve kıyı erozyonun neden olduğu bir diğer önemli çevre sorunu da meydana gelen görsel kirliliktir. Bir yandan Karadeniz Sahil Yolu'nun sürdürülebilir kullanımı; diğer yandan kıyı erozyonunu önlemek amacıyla gruplar halinde T-mahmuzların yapılmış olması, taşınan sedimentin T-mahmuzlar tarafından tutulması, hem T-mahmuzların amaçlanan hedeflerine ulaşmasını hızlandırmakta, hem de balıkçı barınakları ve diğer kıyı yapılarının sığlaşmasını önlemektedir. Bu çalışmada, Doğu Karadeniz Bölümü'nün Rize ve Trabzon illeri sınırları içerisinde bulunan T-mahmuz sistemleri içinden 10 tanesi seçilmiş, son 5 yılda yapılan batimetrik deniz derinliği ölçüm değerleri ve mahmuz topuklarından yaz ve kış sezonunda alınan sediment numuneleri analiz edilmiştir. Elde edilen sonuçlar değerlendirilerek ve eş derinlik eğrileri oluşturulmuş, T-mahmuzların plaj olarak kullanımı ve çevresel etkileri ortaya konulmaya çalışılmıştır. Doğu Karadeniz kıyılarında ilk defa 1998-2000 yılları arasında yapılan Tmahmuzlarının topuklarında 2000-2017 yılları arasında 43.132,38 $\mathrm{m}^{3}$ kum boyutunda sediment birikmiştir. Bu durum Tmahmuzların hem kıyı koruma, hem de plaj olarak kullanılması bakımından çok olumlu bir gelişmedir. T-mahmuzlarının bu şekildeki işlevsel faaliyeti ile hem kıyı erozyonu önlenecek, hem balıkçı barınakları ve diğer kıyı yapılarının sığlaşması azaltılacak, hem de bu alanların plaj olarak kullanılmalarının önü açılmış olacaktır.
\end{abstract}

Anahtar kelimeler: Kıyı erozyonu, Morfoloji, Plaj, T-mahmuz

\begin{abstract}
The eastern Black Sea region of our country has an inclined and rough terrain and the land is consists of by many streams, large and small. In the eastern Black Sea where severe rains are effective, rivers and coastal erosion cause a very important environmental problem. Another important problem is the filling sediment problems along the coast at the points where the combine sea and the streams are carried and the coastal streams. At the same time, this situation it prevents the ports, docks and fishing shelters from filling up and becoming fully functional. As a result of river and coastal erosion, important habitats, coastal settlements are destroyed and consequently serious economic losses occur. Another important environmental problem caused by river and coastal erosion is visual pollution. On the one hand, sustainable use of the Black Sea coastal road; on the other hand, T-head groins were formed in groups in order to prevent coastal erosion, and the sediment retained by $T$-spurs accelerated both $T$ - head groins reaching their intended targets. At the same time T-head groins prevented the fishery harbor and other coastal structures from becoming shallow. In this study, 10 T- head groin systems were chosen from the T-head groins systems within the boundaries of the Rize and Trabzon provinces of the Eastern Black Sea Region and the sediment samples analyzed taken from the spur heels during the summer and winter seasons. The obtained results were evaluated and granulometric measurements were made and co-depth curve were formed and the use of T- head groins as a beach and their environmental impacts have been tried to be demonstrated. Between the years of 2000-2017, $43132.38 \mathrm{~m}^{3}$ sand-weight sediment has been deposited in the heels of the T-head groins performed between 1998-2000 for the first time in the eastern Black Sea coasts. This situation is a very positive development in terms of use of T- head groins as both coastal protection and beach. With this kind of functional activity of T- head groins, both coastal erosion will be prevented and shallowing of fishery harbors and other coastal structures will be reduced as well as, these area will be use as beaches.
\end{abstract}

Keywords: Beach, Coastal erosion, Morphology, T-head groin

\footnotetext{
*c Ayberk KAYA; ayberk.kaya@erdogan.edu.tr; Tel: (0464) 2337518 (dâhili: 1175); Tel: (0464) 23375 14; orcid.org/0000-0001-7278-333X

${ }^{a}$ orcid.org/0000-0001-8251-2461 $\quad{ }^{b}$ orcid.org/0000-0003-2964-1760
} 


\section{Giriş}

Kıyıları korumak amacıyla inşa edilen her türlü mühendislik yapıları, rüzgâr, dalga, akıntı ve akarsu gibi doğal etmenlerin ve insan kaynaklı faktörlerin etkisi altında bulunmaktadır. Bu etkiler ağırlıklı olarak suyun kara ile birleştiği alanlarda görülmekte olup önemli sonuçlar doğurmaktadır. Kıyı bölgesinde deniz hareketlerinin neden olduğu etkili problemlerden bazıları sediment taşınımı ve bunun doğuracağı sonuçlarla ilgilidir. Bu taşınım esnasında etkileşimin doğal bir sonucu olarak kıyı erozyonu dediğimiz aşınma (oyulma) veya kontrolsüz sediment birikmeleri adı verilen dolma ve sığlaşma olayı meydana gelmektedir. Her iki durumda da kıyı çizgisi etkilenmekte ve kı1 topografyasında önemli değişimler meydana gelmektedir. Kiyılarda her ne amaçla olursa olsun inşa yapılan yapılar, kıyıların hidrodinamiğini etkilemekte ve kıyın tabii dengesinin değişmesine neden olmaktadır. $\mathrm{Bu}$ karşılıklı etkileşim yıllardır devam etmekte ve doğal yollarla çalışarak işlemektedir (Süme, 1992).

Mesela, kıyıda sediment taşınım dengesinin bozulması ile liman, balıkçı barınağı, çekek yeri gibi kıyı yapılarının giriş kısımlarında ve basenlerinde kumul birikimi neticesinde sığlaşma oluşumu söz konusudur. Meydana gelen kum yığılması sonucu, yap1 giriş ağzından itibaren su derinliği azalmakta ve balıkçı kayıkları ve teknelerinin giriş ve çıkışları zorlaşmakta, hatta imkânsız hale gelebilmektedir. Bu etkileşim kıyı mühendisliği açısından balıkçı barınakları, limanalar ve çekek yerleri gibi yapılar için sorun oluştururken T-mahmuzlar için ise istenen bir durumdur. T-mahmuzlar, kiyıların korunmas1 amacıyla kum depolanmasını (dolma) sağlamakta ve dalga enerjisini kırıp azaltarak kıy oyulmalarının (kıyı erozyonu) önüne geçmek suretiyle, kıyı eğimini azaltıp kıyının kum ile dolmasını sağlayarak tabii bir plaj görünümü kazandırmak gibi çok önemli bir amaca hizmet ederler (Yüksel vd., 1998).

Doğu Karadeniz Bölümü'nde, 604 km uzunluğundaki Karadeniz Sahil Yolu Sinop'tan başlayarak sınır kapıs1 olan Sarp'a kadar uzanmaktadır. $\mathrm{Bu}$ güzergâh boyunca, kıyı yapılarını ve k1yı boyu devam eden otoyolu korumak amaciyla sira sira T-mahmuz ve kiy1 tahkimatları inşa edilmiştir. Bunların kum, çakıl vb. malzeme ile dolması iyi sonuçlar doğururken, liman, barınak vb. yerlerde ise dolma meydana gelmektedir. Her iki durumda da bölgenin kıyı çizgisi değişmektedir (Özölçer, 1998; Süme vd., 2002; Kırkgöz, 2002; Durmuş, 2007; Süme, 2007;
Bayraktar, 2009; Bayraktar vd., 2016). Ülkemizde özellikle Sinop-Sarp arasında 397 adet T-mahmuz bulunmaktadır. Bunların 75 tanesi Samsun (Orta Karadeniz), 82 tanesi Ordu, 71 tanesi Giresun, 124 tanesi Trabzon, 42 tanesi Rize ve 3 tanesi de Artvin-Arhavi kıyılarında bulunmaktadır. Tmahmuzların 322 tanesi, diğer bir deyişle \% 81'i Doğu Karadeniz kıyılarında bulunmaktadır.

Dünyada ve Türkiye'de hem kıyı koruma amaçlı hem de insanların kiyılardan yararlanmasını sağlayan birçok çalışma mevcuttur. Kıyı-insan iliş̧kisini güçlendiren örneklerden birisi olan Avustralya'da kıyılarda binlerce plaj mevcut olup, bu plajlar kültürel bir yaşam tarzının bir parçasıdır. $\mathrm{Bu}$ sebeple insanların çoğu kıyı şeridinde ya da yakınında yaşamaktadır. Avustralya kıyıları, kıyı-insan etkisinin oldukça başarılı bir şekilde yönetildiği yerlerden biridir (Beale, 1980; Harwey ve Caton, 2003).

Kıyı-insan ilişkisi kapsamında çevre ilişkilerini düzenleyen yasal çalışmalar da yapılmıştır. Halkı doğal kaynak yönetimine dahil etme yöntemleri ve sivil toplum örgütleri ile bu konudaki çalışmalar giderek artmaktadır. Halkın katılımına yönelik işbirlikçi yaklaşımlara yöneticiler ve bilim insanları da daha çok ilgi duymaktadır (Selin ve Chavez, 1995; James, 2000).

Fransa'da ilk defa 1985 yılında uygulanan ve dünyaya yayılan Mavi Bayrak uygulamasının kıyı alanları yönetiminin gelişiminde önemli bir yer tuttuğu söylenebilir. Böylelikle çevresel bilinçlenme artmakta ve kıyıların korunması ve gelecek kuşaklara daha temiz bir çevre bırakılmış olacaktır (Barrow, 1995; Patric vd., 2005; Fışkın vd., 2016).

Bunlara ek olarak bilim insanları, bazı yerel yönetimler ve sivil toplum örgütleri de plaj bölgelerinde kum depolanması kumsal yapının şekli ve malzeme granülometrisi ve çevresel özellikler ile ilgili olarak çalışmalar yapmış ve kıyıların plaj olarak kullanımı ve yönetimi ile ilgili birçok öneriler getirmiştir (Taylor ve Stone, 1996; Abuodha, 2003; Edward, 2017).

\subsection{Plaj Ortamı Modeli}

Plaj ortamları, iç içe geçmiş çok boyutlu çevreyi içine alan, daha büyük kıyı sistemleri içinde ve etkileşimli doğal, sosyo-kültürel ve yönetim sistemleridir (Şekil 1). Plaj ortamlarının doğal (veya biyofiziksel) sistemleri, belirlenen bölge yada çevre için o bölgede bulunan bitki ve hayvan popülasyonunun bütünü olarak isimlendirilen 
biyotadan oluşur. Plajlarda meydana gelen sediment hareketleri (oyulma ve dolma), su etkileşimleri ve ekolojik unsurları şekillendiren süreçler fiziksel olaylar içerisinde değerlendirilir. $\mathrm{Bu}$ sistemler yaklaşı 1-3 km'lik bir açığa ve 20 metrelik su derinliğine kadar oluşabilecek aktif kumul sistemlerini kapsar (Kiy1 Kanunu, 1990; Yüksek, 1995; Bird, 1996; Özölçer vd., 2006; Berkün vd., 2010; Anonim, 2015).

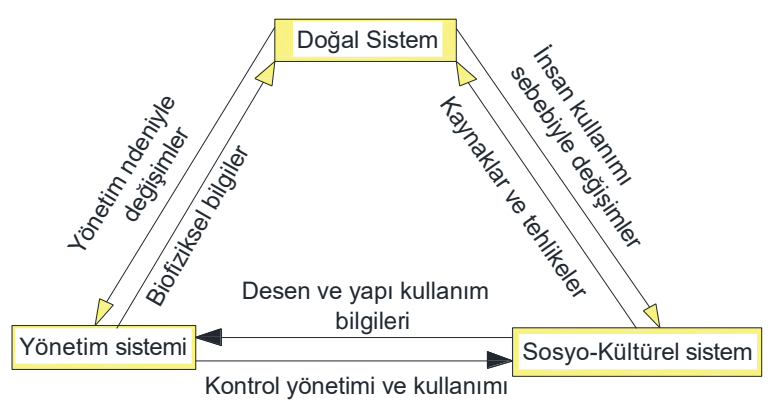

Şekil 1. Üç ana bileşen sistemi (kutu) ve aralarındaki bağlantılar (oklar ve eğik metin) gösteren plaj ortamlarının basit kavramsal modeli (Fişkin vd., 2016)

Böylece doğal plaj sistemleri hem karasal hem de deniz bileşenlerini içerir ve daha geniş bağlamda meydana gelir. Akarsu havzalarındaki her türlü doğal ve beşeri faaliyetler, littoral hücreler ve okyanus süreçleri, plaj ortamlarındaki sosyokültürel sistemler ve kullanım şekilleri plaj sistemleri üzerinde etkilidir. İnsanlar plajları ağırlıklı olarak eğlence (çeşitli rekreasyonel faaliyetler), altyap1 (atık deşarj/depolama), yerleşim ve ekonomik amaçları (turizm, balık tutma, kum madenciliği, vb.) doğrultusunda kullanmaktadır. Plajlar, dinlenme aktiviteleri arasında güneş banyosu, gezi, olta balıkçılığı, yüzme, sörf ve botla gezintinin yanı sıra dolaylı olarak sosyo-kültürel bir simge olarak da kullanılırlar. Plaj ortamlarının yönetim sistemleri devlet kurumları, sivil toplum kuruluşları, kanunlar, tüzükler, politikalar ve programlar vb. gibi birçok etkileşimi kapsamaktadır. Çevresel yönetim, bu sistem içinde en kolay şekilde yer alan yönetim tarzıdır. Plaj ortamlarının yönetim sistemleri bileşeni Şekil 1'de verilmiştir. Yönetim genellikle belirli bir kullanıma, kaynak veya ekonomik sektöre odaklanır (Komar, 1998; Rodney, 2000).

Literatürde bu anlamda sıklıkla kullanılan diğer terimler arasında bütünsel, kapsamlı, bütünleşik ve ekosistem yönetimi bulunmaktadır. Plajların çevre yönetimi: kıyı yönetimi, doğal kaynak yönetimi, kirlilik kontrolü, arazi kullanım planlaması, doğa koruma ve çevre planlama unsurlarını içermektedir. Plaj çevre yönetim politikaları ve yasal çerçeveler; plajların ekolojik tabanlı sürdürülebilir yönetimi ve ekonomik kalkınma için çok önemlidir. Plaj yönetimi hem yasal hem de yasal olmayan araç ve tekniklere dayanır. Etkileşimler, plaj ortamlarını içeren sistemler içinde ve arasında gerçekleşir ve iklim, ekoloji ve jeomorfoloji gibi doğal bilimlerin etkileşimlerini de dikkate alır. Ancak plajların çevre yönetimine etkin bir şekilde rehberlik edecek belirli bir politikanın olduğu pek söylenemez.

Doğal sistemler içinde plajların sosyo-kültürel sistemlerindeki etkileşimleri coğrafya ve psikoloji gibi sosyal bilimlerle yakın ilişki içindedir. Ancak, yönetim sistemleri içinde politik bilimcilerin ve yöneticilerin etkileşimler noktasında endişeleri vardır. Plaj ortamlarının anlaşılması, sunulan plaj çevresi modeli, burada bileşen sistemlerinden herhangi birinin doğru anlaşılması için gerekli olan bağlantıyı sağlar. Burada kullanılan plaj ortamlarının modeli, bu sistemler arasındaki etkileşimleri açıkça belirtir (Şekil 1). Bu tür etkileşimler, doğal kaynaklardan, plaj ortamlarının sosyo-kültürel sistemlerine kadar bir kaynak akışına yol açar. Plaj ortamlarının doğal sistemleri, destekledikleri insan kullanımları ve yönetim tarafindan uygulanan manipülasyonlar tarafından değiştirilmektedir. Yönetim, genellikle insan-kullanımını kontrol etmeye çalışır ve insan kullanımının kalıplarını, süreçlerini, yapılarını ve etkileri hakkında bilgileri ve doğal sistemlerden doğrudan elde edilen biyofiziksel bilgileri belirler. Böylece, doğal sistemleri korumak ve insani yarar sağlamak için aralarındaki bağlantılar, etkileşimler plaj ortamının tüm bileşen sistemlerinde dikkate alınmalıdır.

\subsection{Plaj Oluşumunda Kıyı}

Kumsal kavramı, kumlu sahil morfolojisinin incelenmesinde büyük önem taşımaktadır. Kum plajlarının davranışı, zamansal ve mekânsal olarak birkaç yüzyıldaki kıyı evrimi ölçeğinden saniyedeki dane etkileşimlerine bağlı olarak değişen ölçekler üzerinde incelenebilir. Bu süreçte plaj sisteminin her biri kendi mekânsal ve zamansal ölçeği olan bir bölüm hiyerarşisinden oluştuğu görülebilir.

Yüksek mertebeden bir bölüm, düşük mertebeli bölmeleri içerir ve bu nedenle yüksek mertebeden bir bölme, daha geniş bir zamansal ve mekânsal ölçeğe sahiptir. Bir kıyı sisteminde belli bir 
bölmede zamansal ve mekânsal ölçekler arasında yakın bir bağ oluşturduğu varsayılır ve bu birleşim birincil ölçek ilişkisi olarak adlandırılır. Yani kıyı akıntıları neticesinde sahilde biriken malzemenin hem granülometrisi hemde hacmi zamanla değişiklik gösterir. Bunda özellikle kıyının morfolojisi etkilidir. Fakat zamanla mekandaki türbülans oluşumu, denizin kabarması veya alçalması (gelgit), dalga yüksekliklerindeki değişimler, ve gelgit harici farklı nedenlerle deniz seviyesindeki değişimler çok daha etkili olmaktadır. $\mathrm{Bu}$ etkilerde plaj profilinde, plaj kıvrımlarının oluşması, aşırı yığılmalar, hızlı oyulmalar, kum tepecikleri vb. etkileri doğurur. Sonuç olarak plajın bulunduğu mekânda zamana bağl1 olarak sahil uzunluğu değişiklik gösterir (Şekil 2).

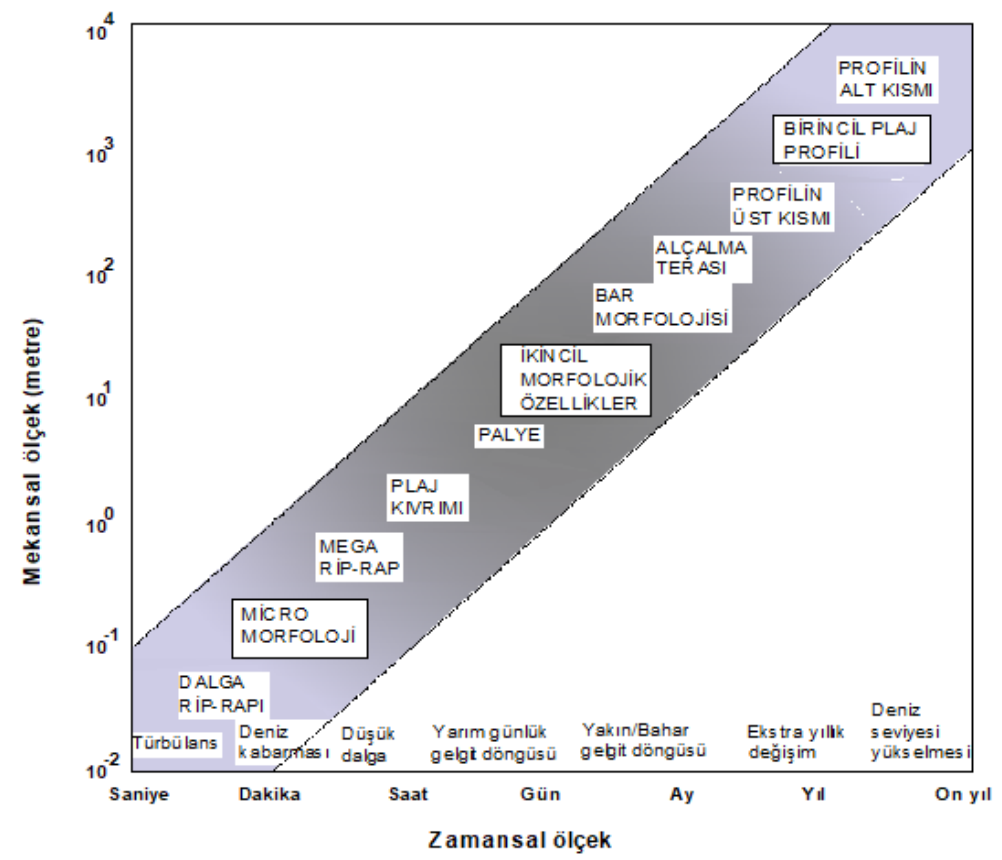

Şekil 2. Kumlu plajlarla ilişkili morfolojik özelliklerin mekânsal ve zamansal ölçekleri ile akışkan hareketleri arasındaki ilişki (Rodney, 2000)

Morfodinamik konsept, ayrıca, morfolojiden etkilenen ve kontrol eden fiziksel süreçlerin (dalgalar, gelgitler, akımlar ve tortu taşınımı), benzer mekânsal ve zamansal ölçeklerde ilgi konusu morfolojik özellik olarak ortaya ç1kabileceğini gösterir. Genel plaj profili birincil plaj profili olarak adlandırılır ve yaklaşık olarak düzlemsel bir plaj yüzü ve içbükey yukarı doğru kıyıya yakın profilden oluşur.

$\mathbf{h}=\mathbf{A y}{ }^{\mathbf{m}}$

Burada h su derinliği, A boyutlu bir parametre, y karaya yakın mesafe ve $\mathrm{m}$ boyutsuz bir üstür. Doğal plaj profillerinin denge plaj profili denklemine titizlikle uydurulmas1, ortalama $\mathrm{m}=$ 2/3 değerinin alınması önerilmektedir ve bu değer kıyı eğimini ifade eder. Ortaya çıkan profilin eğimi A tarafindan kontrol edilir ve tortu boyutu ile orant1li olarak artar.
Birincil plaj profili ile ilişkili zamansal ve mekânsal ölçekler sırasıyla yıllar ve kilometrelerdir. Sahanın hidrodinamik koşullarla (esasen deniz seviyesi) dengede olduğu ve profil dengesini sağlamak için yeterli sediment sağlandığı varsayımı altında, içbükey yukarı doğru kıyı kısmı basit bir parabolik işlevle tanımlanabilir.

$$
A=0.067 w_{s}^{0.44}
$$

Burada, yatak malzemesinin sediment düşme hızı $\mathrm{w}_{\mathrm{s}}$ 'dir. Günümüzde, A ve $\mathrm{m}$ parametrelerinin evrenselliği önemli tartışmaları beraberinde getirmektedir. Aslında, bir kumsalın hidrodinamik koşullarla dengede olabileceği fikri kuvvetle sorgulanmaktadır. Bununla birlikte, denge plaj1 kavramı, deniz seviyesinin kumlu sahil şeridindeki artışını öngörmede en yaygın kullanılan yaklaşımdır (Masselink ve Kroon, 2017). 


\section{3. Çalışma Alanı}

$\mathrm{Bu}$ çalışmada, Rize-İyidere ve Trabzon-Of ilçelerinde bulunan üç T-mahmuz gurubundan $\mathrm{Bu}$ mahmuz gruplarından Kiyıcık'ta 13, Eskipazar'da 10 ve İyidere'de 8 adet T-mahmuz bulunmaktadır) Kiyıcik'tan 4, Eskipazar'dan 3 ve İyidere'den de 3 adet T-mahmuz olmak kaydiyla seçilen toplam 10 adet $\mathrm{T}$-mahmuzun sediment biriktirme ve plaj olarak kullanılabilirliği irdelenmiştir (Şekil 3).
Çalı̧̧ma alanının batısında Kıyıcık ve Eskipazar ile doğusunda İyidere T-mahmuz gurupları uzunluk olarak yaklaşık $6.5 \mathrm{~km}$ 'dir. Bu alanda Of limanı ile 2 adet balıkçı barınağ bölge Türkiye'de yağış yüksekliğinin en yüksek olduğu yer olup, ortalama yağış yüksekliği 2000 $\mathrm{mm}$ civarındadır ve buralardan denize ulaşan çok sayıda küçük büyük akarsu mevcuttur.

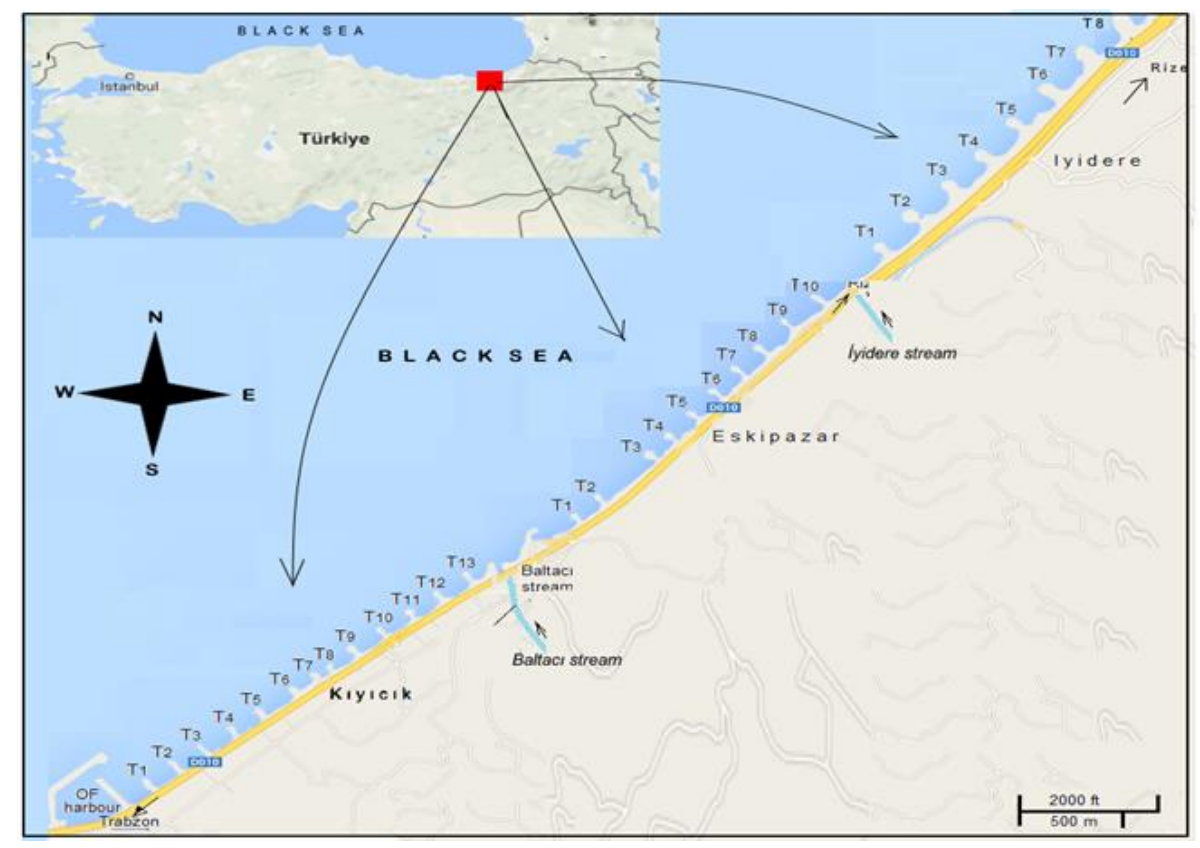

Şekil 3. Çalışma alanına ait yer bulduru haritası

Havza eğimi oldukça diktir. Aşağı ve orta yükseltilerdeki ormanlık alanların büyük bir kısmı tahrip edilerek çay plantasyonlarına dönüştürülmüştür. Bölgede meydana gelen erozyon, seltaşkın olayları sonucunda dikkate değer hacimde kum-çakıl akarsular tarafından denize taşınmaktadır. Taşınan bu sedimentler T-mahmuz sistemlerinin bulunduğu yerlerde dolma sürecinin önemli miktarını oluşturur. Bu bölgede sürekli olarak dalga ölçümleri yapılmaktadır. Etkin dalga yönü olarak Kuzey (N), Kuzey-Kuzey Bat1 (NNW) ve Kuzey Batı (NW), ortalama belirgin dalga yüksekliği olarak da $1.5-2.0 \mathrm{~m}$ ve dalga periyotları ise 4.5-8.0 s olduğu belirlenmiştir, Kat1 madde taşınımı ise batı-doğu yönündedir.

\section{Materyal Metot}

$\mathrm{Bu}$ çalışmada, Rize-İyidere'de 8'li bir grup ve Trabzon-Of ilçesi Kıyıcık mevkiinde 13'lü bir grup ve Eskipazar mevkiinde ise 10'lu bir grup olmak üzere toplam 31 adet T-mahmuz bulunmakta olup bunlardan 4 tane Kiyıc1k'tan, 3'er tanede Eskipazar ve İyidere'den seçilen 10 adet T-mahmuz ele alınmıştır. $\mathrm{Bu}$ mahmuz gruplarının plaj olarak kullanılabilirlikleri incelenmiştir. Çalışmada adı geçen Tmahmuzlarda Süme (2009) tarafından sonar yardımıyla su derinlikleri ölçümleri yapılmış, farklı zamanlarda dolma süreçleri incelenmiş, tutulan malzeme miktarı etüt edilmiştir (Şekil 4). Araştırma konusu T-mahmuzların 23 adedi Trabzon ili Of ilçesi sınırları, 8 adedi ise Rize ili sınırları içerisinde yer almaktadır. Of ve Rize'deki mahmuzların bulunduğu kıyının uzunluğu yaklaşık $20 \mathrm{~km}$ olup, bu sahilde kıyı batimetrisini etkileyen Of limanı ve 2 adet balıkçı barınağı mevcuttur (Süme, 2014; Süme ve Yüksek, 2018). Çalışma kapsamında değerlendirilen, Trabzon ve Rize illerindeki 31 adet T-mahmuz civarındaki derinlik ölçümleri ve sediment biriktirme hesapları 2000, 2009, 2013 ve 2017 yıllarinda Süme tarafindan yapılmıştır. 


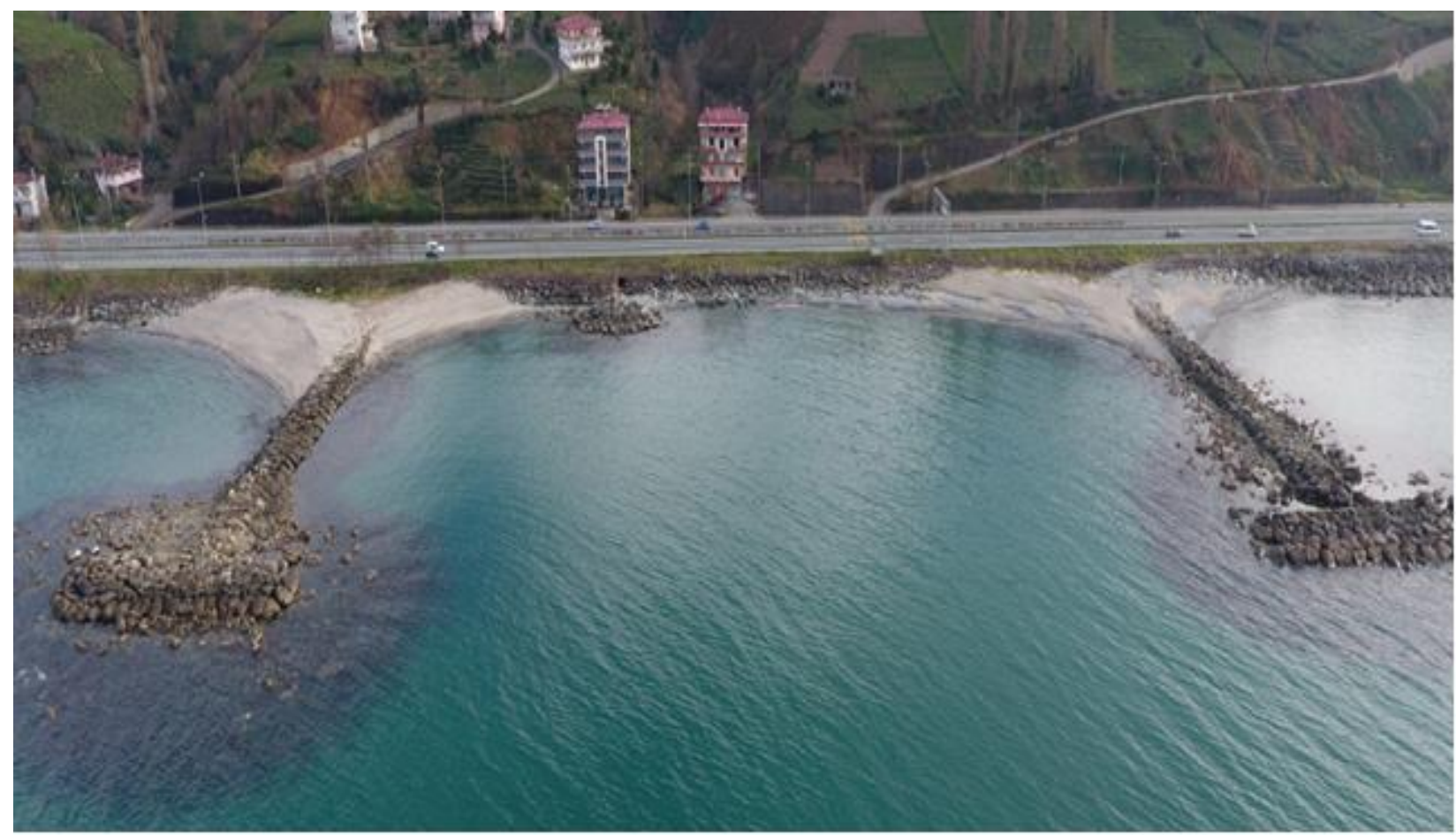

Şekil 4. Kıyıcık bölgesindeki 2 adet T-mahmuzların genel görünüşü (Yaz başı)

Sonar yardımıyla ölçüm yapılmadan önce, mahmuzlar arası $5 \times 5$ metrelik karelaj oluşturularak numaralandırılmış ve arazi üzerinde işaretlenmiştir. Daha sonra üzerinde sonar kurulu olan bot ile karelajin tahmini kesim noktalarına gelinerek deniz derinlik değerleri okunmuş ve kaydedilmiştir. NetCAD programında işlem yapabilmek için önce işaretlenen noktalardaki derinlik değerlerinden bir Excell veri dosyası oluşturularak, NetCAD-Pro programı ile bu noktalar ve derinlik değerleri okutturulmak suretiyle sayısallaştırılmıştır.

Ölçülen veriler yardımıyla T-mahmuzların batimetrik eş yükselti eğrileri oluşturulmuş ve hacim hesapları yapılmıştır. İncelenen $\mathrm{T}$ mahmuzlarda öncelikle, toplam topuk alanları (AT) hesaplanmış, T-mahmuzlar yapılmadan önce ve farklı yıllarda alınan verilerden yararlanılarak topuklardaki ortalama su derinlikleri ölçülmüş ve topuktaki tüm derinliklerin aritmetik ortalamas1 alınarak (dh) ortalama dolma derinlikleri elde edilmiştir. O yıla ait ortalama derinlikler bir önceki yıla ait ortalama derinliklerden çıkarılarak ortalama derinlik değişimine ait farklar $(\Delta \mathrm{h})$ bulunmuştur. Daha sonra ise, topuk alanlar ile ortalama derinlikler çarpılarak her mahmuzda biriken ölçüm dönemlerine ait sediment hacmi (VT) hesaplanmış ve her mahmuz için yapıldı ğ 1 yıl ile 2017 yılına kadar geçen sürede biriktirdiği toplam sediment hacmi ( $\mathrm{VTT}$ ) hesaplanmıştır.
Çalıșma kapsamında bulunan T-mahmuzlar Şekil 3 'te gösterilmektedir.

NOT: Benzer bir çalışma Süme ve Tansel (2016) tarafindan yapilan ve Ocean \& Coastal Management adlı dergide yayınlanan, "Capacity building for field inspections: A comprehensive assessment tool for monitoring structural integrity and sediment capture performance of T-head groins" adlı makalede detaylı açıklanmıştır.

\section{Bulgular}

Trabzon ilindeki T-mahmuzlara maksimum sediment toplanma zamanları birbirinden farklıdır. Kiyıcıktaki 3 farklı T-mahmuzda (T1, T10 ve T13) en yüksek sediment hacimleri 2000-2009 y1lları arasinda elde edilirken; T7 numaralı mahmuzda en yüksek sediment hacmine 20132017 yılları arasında rastlanmıştır (Tablo 1). Kıyıcıktaki 4 farklı (T1, T7, T10 ve T13) mahmuzlarında en düşük sediment hacmine 20092013 yılları arasında ulaşılmıştır.

Kıyıcıktaki T-mahmuzlarında en düşük sediment hacmi $\left(446.875 \mathrm{~m}^{3}\right)$ ve en yüksek sediment hacmi $\left(3092.375 \mathrm{~m}^{3}\right)$ değerlerine T13 numaralı mahmuzda rastlanmıştır. Kıyıcıktaki 4 adet Tmahmuzunda $7150 \mathrm{~m}^{2}$ lik alanda $23505.63 \mathrm{~m}^{3}$ sediment depolanmıştır. Buna göre Kıyıcıkta 1 $\mathrm{m}^{2}$ de $3.29 \mathrm{~m}^{3}$ sediment depolanmıştır (Şekil 3). 
Eskipazar'daki 3 farklı T-mahmuzda en yüksek sediment hacmine $\left(2341.625 \mathrm{~m}^{3}\right)$ 2013-2017 yılları arasında rastlanırken; en düşük sediment hacmine $\left(429.000 \mathrm{~m}^{3}\right)$ ile 2009-2013 y1llar1 arasında rastlanmıştır (Tablo 1).

Eskipazar'daki 3 adet T-mahmuzunda 5362.5 $\mathrm{m}^{2}$ lik alanda $12584 \mathrm{~m}^{3}$ sediment depolanmıştır.
Buna göre Eskipazar'da $1 \mathrm{~m}^{2}$ ' de $2.34 \mathrm{~m}^{3}$ sediment depolanmıştır. İyidere'deki 3 farklı Tmahmuzunda en yüksek sediment hacmine $\left(1662.375 \mathrm{~m}^{3}\right)$ 2013-2017 y1llar1 arasinda T-5 mahmuzunda rastlanırken; en düşük sediment hacmine $\left(303.875 \mathrm{~m}^{3}\right)$ ile 2009-2013 y1llar1 arasında T1-mahmuzunda rastlanmıştır (Tablo 1).

Tablo 1. Yıllara göre derinlik değişimi ve sediment birikimi

\begin{tabular}{|c|c|c|c|c|c|c|c|c|}
\hline \multicolumn{2}{|c|}{$\begin{array}{l}\text { T-mahmuzun } \\
\text { Bulunduğu Yer } \\
\text { ve Mahmuz No }\end{array}$} & \multirow{2}{*}{$\begin{array}{c}\begin{array}{c}\text { Yapım ve } \\
\text { Ölçüm } \\
\text { Yılları }\end{array} \\
2000(\mathrm{YY})\end{array}$} & $\begin{array}{c}\text { Mahmuz Alanı } \\
\left(\mathrm{A}_{\mathrm{T}}\right) \\
\left(\mathrm{m}^{2}\right)\end{array}$ & \multirow{2}{*}{$\begin{array}{c}\text { Ortalama } \\
\text { Derinlik } \\
\left(\mathrm{d}_{\mathrm{h}}\right) \\
(\mathrm{m})\end{array}$} & \multirow{2}{*}{$\begin{array}{l}\text { Değişim } \\
\text { Periyodu } \\
- \\
\end{array}$} & \multirow{2}{*}{$\begin{array}{c}\text { Ortalama } \\
\text { Derinlik } \\
\text { Değişimi } \\
\left(\Delta_{\mathrm{h}}\right) \\
\quad(\mathrm{m}) \\
-\end{array}$} & \multirow{2}{*}{$\begin{array}{c}\text { Sediment } \\
\operatorname{Hacmi}\left(\mathrm{V}_{\mathrm{T}}\right) \\
\left(\mathrm{m}^{3}\right) \\
\\
-\end{array}$} & \multirow[t]{2}{*}{$\begin{array}{c}\text { Dolma Hacmi } \\
(2000-2017) \\
\left(\Sigma \mathrm{V}_{\mathrm{T}}\right) \\
\left(\mathrm{m}^{3}\right)\end{array}$} \\
\hline \multirow{16}{*}{ 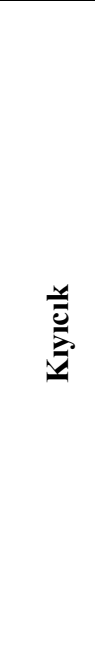 } & \multirow{4}{*}{ T1 } & & \multirow{4}{*}{1787.5} & & & & & \\
\hline & & 2009 & & -1.26 & $2000-2009$ & -1.63 & 2913.625 & \multirow{3}{*}{5684.255} \\
\hline & & 2013 & & -0.92 & $2009-2013$ & -0.34 & 607.750 & \\
\hline & & 2017 & & 0.29 & $2013-2017$ & 1,21 & 2162.880 & \\
\hline & \multirow{4}{*}{$\mathbf{T 7}$} & $2000(\mathrm{YY})$ & \multirow{4}{*}{1787.5} & -2.9 & - & - & - & \multirow{4}{*}{6542.250} \\
\hline & & 2009 & & -1.3 & $2000-2009$ & -1.6 & 2860.000 & \\
\hline & & 2013 & & -0.94 & $2009-2013$ & -0.36 & 643.500 & \\
\hline & & 2017 & & 0.33 & 2013-2017 & -1.27 & 3038.75 & \\
\hline & \multirow{4}{*}{ T10 } & $2000(\mathrm{YY})$ & \multirow{4}{*}{1787.5} & -2.88 & - & - & - & \multirow{4}{*}{5523.375} \\
\hline & & 2009 & & -1.2 & $2000-2009$ & -1.68 & 3003.000 & \\
\hline & & 2013 & & -0.94 & $2009-2013$ & -0.26 & 464.750 & \\
\hline & & 2017 & & 0.21 & $2013-2017$ & 1.15 & 2055.625 & \\
\hline & \multirow{4}{*}{ T13 } & $2000(\mathrm{YY})$ & \multirow{4}{*}{1787.5} & -2.93 & - & - & - & \multirow{4}{*}{5755.750} \\
\hline & & 2009 & & -1.2 & $2000-2009$ & -1.73 & 3092.375 & \\
\hline & & 2013 & & -0.95 & $2009-2013$ & -0.25 & 446.875 & \\
\hline & & 2017 & & 0.29 & $2013-2017$ & 1.24 & 2216.50 & \\
\hline \multirow{12}{*}{ 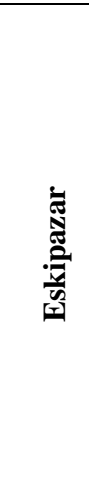 } & \multirow{4}{*}{ T1 } & $2000(\mathrm{YY})$ & \multirow{4}{*}{1787.5} & -2.18 & - & - & - & \\
\hline & & 2009 & & -1.27 & $2000-2009$ & -0.91 & 1626.625 & 4147000 \\
\hline & & 2013 & & -0.97 & $2009-2013$ & -0.3 & 536.250 & $414 \% .000$ \\
\hline & & 2017 & & 0.14 & $2013-2017$ & 1.11 & 1984.125 & \\
\hline & & $2000(\mathrm{YY})$ & & -2.17 & - & - & - & \\
\hline & $\mathbf{T 7}$ & 2009 & 17875 & -1.16 & $2000-2009$ & -1.01 & 1805.375 & 4225750 \\
\hline & 17 & 2013 & $1 / 81.5$ & -0.9 & $2009-2013$ & -0.26 & 464.750 & 4325.750 \\
\hline & & 2017 & & 0.25 & $2013-2017$ & 1.15 & 2055.625 & \\
\hline & & $2000(\mathrm{YY})$ & & -1.94 & - & - & - & \\
\hline & & 2009 & 17875 & -1.19 & $2000-2009$ & -0.75 & 1340.625 & \\
\hline & T10 & 2013 & $1 / 87.5$ & -0.95 & $2009-2013$ & -0.24 & 429.000 & 4111.250 \\
\hline & & 2017 & & 0.36 & $2013-2017$ & 1.31 & 2341.625 & \\
\hline & & $2000(\mathrm{YY})$ & & -3.02 & - & - & - & \\
\hline & & 2009 & & -2.63 & $2000-2009$ & -0.39 & 697.125 & \\
\hline & T1 & 2013 & 1787.5 & -2.46 & 2009-2013 & -0.17 & 303.875 & 2198.625 \\
\hline & & 2017 & & -1.79 & $2013-2017$ & -0.67 & 1197.625 & \\
\hline & & $2000(\mathrm{YY})$ & & -3.22 & - & - & - & \\
\hline : & T5 & 2009 & 17875 & -2.91 & $2000-2009$ & -0.31 & 554.125 & 2663375 \\
\hline 童 & 15 & 2013 & $1 / 81.5$ & -2.66 & $2009-2013$ & -0.25 & 446.875 & 2663.375 \\
\hline & & 2017 & & -1.73 & $2013-2017$ & -0.93 & 1662.375 & \\
\hline & & $2000(\mathrm{YY})$ & & -3.13 & - & - & - & \\
\hline & & 2009 & & -2.9 & $2000-2009$ & -0.23 & 411.125 & \\
\hline & T8 & 2013 & 1787.5 & -2.65 & $2009-2013$ & -0.25 & 446.875 & 2180.750 \\
\hline & & 2017 & & -1.91 & $2013-2017$ & -0.74 & 1322.750 & \\
\hline
\end{tabular}


İyidere'deki 3 adet T-mahmuzunda $5362.5 \mathrm{~m}^{2}$ 'lik alanda $7042.75 \mathrm{~m}^{3}$ sediment depolanmıştır. Buna göre İyidere'de $1 \mathrm{~m}^{2}$ de $1.31 \mathrm{~m}^{3}$ sediment depolanmıştır. Lokasyonlara göre sediment verimi batıdan doğuya gidildikçe doğrusal biçimde azalmaktadır. Lokasyonlara göre en yüksek sediment verimine Kıyıcık'taki T-mahmuzlarında rastlanırken; en düşük sediment verimine İyidere'deki T-mahmuzlarında rastlanmıştır (Tablo 1, Şekil 5).

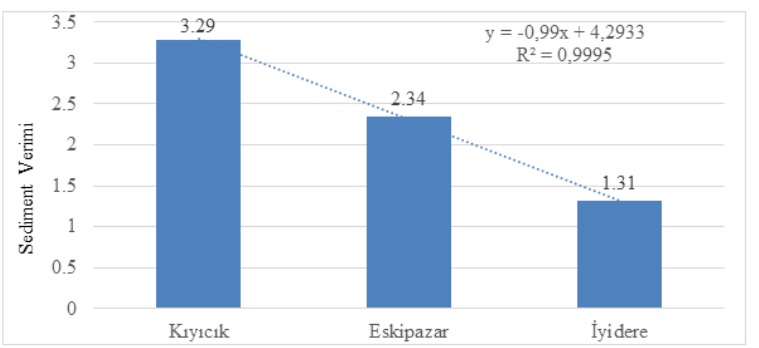

Şekil 5. Lokasyonlardaki sediment verimleri $\left(\mathrm{m}^{3} / \mathrm{m}^{2}\right)$

Tablo 1'de verilen değerler T-mahmuzların yapıldığı yıllardaki (YY) ölçümler ile 2009, 2013 ve 2017 y1lı yaz ve kış sezonunda elde edilen batimetrik değerler ve bunlara ait hesaplamalar görülmektedir. $\mathrm{Bu}$ değerler yaz ve kış dönemine (dh) ait ölçümler olup, veri alınan T-mahmuz topuklarındaki batimetrik derinliklerin ortalaması alınarak oluşturulmuştur. $\mathrm{Bu}$ çalışmalar neticesinde kıyı boyu devam eden T-mahmuzların sediment birikimi sağlayanlarının plaj olarak kullanımının çok uygun olduğu görülmüştür. Özellikle sağ ve sol topuklar (mahmuz havuzu) denizden yararlanma anlamında çok uygun ve güvenlidir (Şekil 6). Doğu Karadeniz gibi kıyı morfolojisinin çok değişken ve dalgalarının hırçın olduğu düşünülürse plaj olarak T-mahmuzların kullanımı önem arz etmektedir (Süme ve Tansel, 2016).

\section{Sonuçlar ve Öneriler}

Bu çalışmada, Doğu Karadeniz'de, Trabzon ili Of ilçesinde 23 ve Rize ili İyidere ilçesinde 8 tane olmak üzere inşa edilen toplam 31 adet $\mathrm{T}$ mahmuzdan 10 adet T-mahmuzun y1llara göre dolma süreçleri değerlendirilmiştir. Yapıların topuklarında (mahmuz havuzu) çeşitli yıllarda yapılan derinlik ölçümü verileri yardımıyla $(\Delta \mathrm{h})$ ortalama su derinlikleri bulunmuş, araştırma yapılan T-mahmuzların tamamında net olarak sediment birikiminin (dolma) olduğu ve sürecin devam ettiği görülmüştür.

Araştırılan diğer 31 adet T-mahmuz içinde 21 tanesinin ise, neredeyse hiç malzeme biriktirmediği ve bu yapılarda önemli bir oyulma probleminin olmadı̆g 1 işlevlerini tam olarak yapabilmeleri için gerekirse suni besleme yapılarak gerekli önlemlerin alınması kaçınılmaz olduğu görünmektedir.

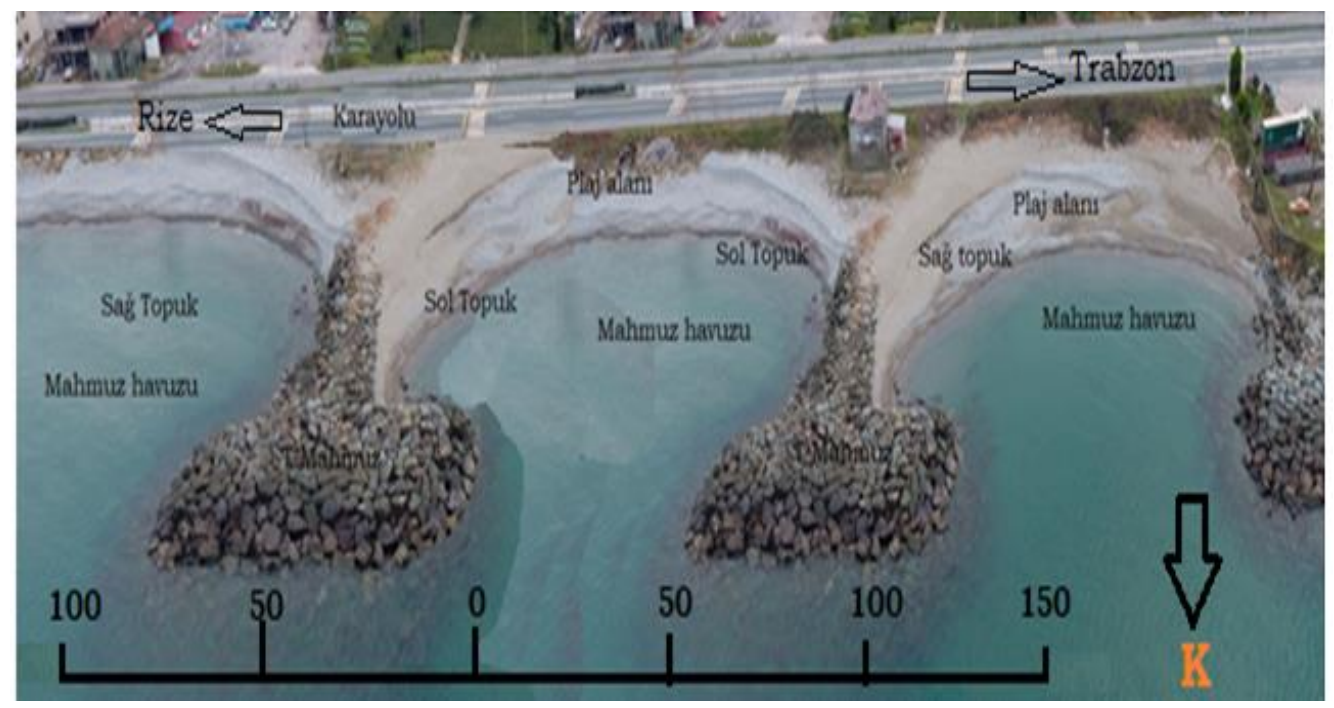

Şekil 6. T-mahmuz bölgesi tanımlamaları

Yapıların topuklarında ve çevrelerinde sediment depolanmasının gerçekleşmesinde etkili olan yapı faktörleridir. Bunlar dolmayı etkileyen tali mendireklerin varlığı, ani derinlik değişimi ve çevre ile ilgili faktörlerdir. Yapının memba tarafında akarsuyun olup olmaması önemli bir faktör olarak gözükmektedir. Ayrıca civardaki balıkçı barınakları gibi sediment tutucu diğer 
yapıların olup olmaması da dolma sürecine etki eden faktörler olduğu görülmektedir.

Genellikle, Doğu Karadeniz Sahil Yolu bitirildikten sonra (2007 y1lında) kiyıların korunması ve rekreasyon amacıyla inşaa edilen türlü türlü yapıların (balıkçı barınağı, çekek yeri, tahkimatlar, spor amaçlı tesisler, suni besleme vb.) kıyıların tabii dengesi üzerinde önemli rol oynamakta, oyulma ve dolma süreçlerini artırmaktadır. Yine bölgeden kontrolsüz kum alımı da çok önemli bir sorun olarak gözükmektedir. Kontrollü sediment birikimini sağlamak ve/veya artırmak amacıyla değişik yapısal önlemler alınabilir. Arazi çalışması, fiziksel ve matematiksel model çalışması yapılabilir. Öte yandan, tedbir almak bazı sahil bölgelerinde yarar sağlarken, başka bölgelerde erozyon, sığlaşma gibi kıyıların yapısal stabiliteleri üzerinde zararlı olabilir.

Ayrıca mahmuz yapıları üzerinde dalgalardan kaynaklanan deformasyonların sediment depolanmasina olumsuz etkileri olmamaktadır. Çünkü mahmuzların kret kotları deniz seviyesinden $+0,50 \mathrm{~m}$ yükseklikte olmas1 gerekirken, bu yükseklik $1 \mathrm{~m}$ civarındadır. Yapıda oluşan deformasyonlar aslında yapının ideal seviyeye inmesine yardımcı olmuştur. Haliyle dalgaların kıyıya ulaşmaları kolaylaşmış ve sediment birikimine de olumlu katkı sağlamıştır. Zaten T-mahmuzlardan beklenen nihai sonuç, Tmahmuzların yapımından sonra, sediment tarafindan örtülerek zamanla tamamen kaybolmaları ve kıyının doğal bir yapıya kavuşmasına yardımcı olmalarıdır.

Başka bir deyişle, T-mahmuzların dolması veya oyulma problemleri olan sahil şeridinde, meydana gelen deniz seviyesi değişimlerinin de etkisi olabileceği unutulmamalıdır. Civarda 2011 yılından sonra yürütülen ve devam eden bir proje sonuçlarına göre de yaklaşık $15-53 \mathrm{~cm}$ arasında bir deniz seviyesi değişimi olduğu görülmüştür. $\mathrm{Bu}$ duruma göre de seviye değişimi önemli bir parametre olarak gözükmektedir. Hülasa, özellikle geceleri ve fırtına sonrası aşırı değer artışı ölçülmektedir. Eş derinlik ölçümleri denizin nispeten durgun olduğu saatlerde yapıldığ 1 için etkileşim artı veya eksi yönde pek fazla sonuca etkili olmamaktadır (Taylor ve Stone, 1996; Süme, 2011).

Zamanla öyle ki bu süre çok değişken olmakla birlikte, T-mahmuzlar ve civarının tahminen otuz y1l içerisinde sediment tarafindan örtülerek tamamen dolmalar1 ve kaybolmalar1 beklenmektedir. Ancak o zaman kıyı doğal yapısına kavuşacak ve çevreyle tam uyumlu hale gelecek ve plaj olarak kullanımına gerçek manada devam edebilecektir.

\section{Kaynaklar}

Abuodha, J.O.Z., 2003. Grain size distribution and composition of modern dune and beach sediments, Malindi Bay coast, Kenya. Journal of African Earth Sciences, 36, 41-54.

Anonim, 2015. Kıyı Yapıları Planlama ve Tasarım Teknik Esasları. TC Ulaştırma, Denizcilik ve Haberleşme Bakanlığı Altyapı Yatırımları Genel Müdürlüğü (AYGM) yayını. Ankara, $437 \mathrm{~s}$.

Barrow, C.J., 1995. Developing the Environment: Problems and Management. Longman, Essex, $313 p$.

Bayraktar, E.A., 2009. Doğu Karadeniz Kıyılarında Tmahmuzlarının Kıyıya Etkileri ve Balıkçı Barınaklarının Sığlaşması. Yüksek Lisans Tezi, Karadeniz Teknik Üniversitesi, Fen Bilimleri Enstitüsü, Trabzon.

Bayraktar, E.A., Bayraktar, D. ve Yüksek, Ö., 2016. Doğu Karadeniz kıyılarında T-mahmuzlarının kıyıya etkileri. Süleyman Demirel Üniversitesi, Fen Bilimleri Enstitüsü Dergisi, 20 (3), 509517.

Beale, J.G., 1980. The Manager and the Environment: General Theory and Practice of Environmental Management. Pergamon, Oxford, 192p.

Berkün, M., Anılan, T. ve Aras, E., 2010. Doğu Karadeniz Bölgesi'nde sediment taşınması ve kıyı erozyonu etkileşimleri. Türkiye Mühendislik Haberleri, TMH-461-462-2010/34, 47-52.

Bird, E.C.F., 1996. Beach Management. Wiley, 281p.

Durmuş, C., 2007. Mersin Bölgesi Kıyı Koruma Yapılarının İncelenmesi. Yüksek Lisans Tezi, Çukurova Üniversitesi, Fen Bilimleri Enstitüsü, Adana.

Edward, J.A., 2017. Beach Plains: Formation, Evolution and Ecological Significance Coastal Geomorphology and Shoreline Management Unit. Université du Littoral Côte d'Opale, France.

Fışkın, R., Çakır, E. ve Özkan, E.D., 2016. Mavi bayrak uygulamasının önemi, ölçütleri ve ülkelere göre durum değerlendirmesi. Mehmet Akif Ersoy Üniversitesi Sosyal Bilimler Enstitüsü Dergisi, 8 (15), 224-247.

Harwey, N. ve Caton, B., 2003. Commonwealth of Australia, Living on the Coast: the 
Commonwealth Coastal Policy. Department of the Environment, Sport and Territories, Canberra.

James, R.J., 2000. The first step for the environmental management of beaches: establishing an effective policy framework. Coastal Management, 28 (2), 149-160.

Kırkgöz, M.S., 2002. Kıy1 Erozyonunun Boyutları. Türkiye Mühendislik Haberleri, TMH-420-421422, 71-73.

Kıyı Kanunu, 1990. Kanun No: 3621, Kabul Tarihi: 4/4/1990.

Komar, P.D., 1998. Beach Processes and Sedimentation. Prentice-Hall, New Jersey, $544 \mathrm{p}$.

Masselink, G. ve Kroon, A., 2017. Coastal Zones and Estuaries. Morphology and Morphodynamics of Sandy Beaches, 8s.

Özölçer, İ.H., 1998. Kıyı Korumasında Mahmuzların Etkilerinin Araştırılması. Doktora Tezi, Karadeniz Teknik Üniversitesi, Fen Bilimleri Enstitüsü, Trabzon.

Özölçer, İ.H., Kömürcü, M.İ., Birben, A.R., Yüksek, Ö. ve Karasu, S., 2006. Effects of T-Shape Groin Parameters on Beach Accretion. Ocean Engineering, 33, 382-403.

Patrick, A.H., Sergio, R.D., Eduardo G.B., Luiz J.T., Ricardo N.A., Luciana S.E., Nelson, S.G., Elirio E.T., Luiz, C., De A.T. ve Luiz C.P.C., 2005. Beach ridges, foredunes or transgressive dunefields? Definitions and an examination of the Torres to Tramandaí barrier system, Southern Brazil. Anais da Academia Brasileira de, 77 (3).

Rodney J.J., 2000. From beaches to beach environments: linking the ecology, human-use and management of beaches in Australia. Ocean and Coastal Management, 43, 495-514.

Selin, S. ve Chavez, D., 1995. Developing a collaborative model for environmental planning and management. Environmental Management, 19 (2) 189-195.
Süme, V. ve Karasu, S., 2002. Rize Sahilinde İyidereÇayeli Arasında Yapılan T-mahmuzların Kıyı Koruma Açısından İncelenmesi. 4. Ulusal Kıyı Mühendisliği Sempozyumu, 24-27 Ekim, Antalya, s201-217.

Süme, V. ve Tansel, B., 2016. Capacity building for field inspections: A comprehensive assessment tool for monitoring structural integrity and sediment capture performance of T-head groins. Ocean and Coastal Management, 125, 20-28.

Süme, V. ve Yüksek, T., 2018. Doğu Karadeniz Kıyılarının Kumsal Özellikleri ve Plaj Profilleri. 9. Kıyı Mühendisliği Sempozyumu, 1-3 Kasım, Adana, s84-95.

Süme, V., 1992. Deniz Yapılarının Dinamik Projelendirilmesi ve Stabilite Etüdü. Yüksek Lisans Tezi, Karadeniz Teknik Üniversitesi, Fen Bilimleri Enstitüsü, Trabzon.

Süme, V., 2007. Rize İyidere-Çayeli Arasındaki TMahmuzların Kıyı Koruma Açısından İncelenmesi, 6. Ulusal Kıyı Mühendisliği Sempozyumu, 25-28 Ekim, İzmir, s25-34.

Süme, V., 2009. Rize-Çayeli Arası ve BozukkaleÜnye Çimento Mevkii Arası Kübaj Çalışması. Etüt Raporu, 15s.

Süme, V., 2011. Rize’de Deniz Seviyesi Değişimi. Recep Tayyip Erdoğan Üniversitesi, Bilimsel Araştırma Projesi, Rize.

Süme, V., 2014. Grain size and beach formation characteristic at the t-head groins system at Kıyıcık, Turkey (Eastern Black Sea). Journal of Civil and Environmental Engineering, 4 (4), 15.

Taylor, M. ve Stone, G.W., 1996. Beach-Ridges: A Review. Journal of Coastal Research, 12 (3), 612-621.

Yüksek, Ö., 1995. Effects of Breakwater Parameters on Shoaling of Fishery Harbors. Journal of Waterway, Port, Coastaland Ocean Engineering, 121 (1), 13-22.

Yüksel, Y., Çevik, E. ve Çelikoğlu, Y., 1998. Kıyı ve Liman Mühendisliği. İnşaat Mühendisleri Odası, İstanbul, s187-189. 